\title{
EDUCATION
}

\section{Using a Theatre Approach to Develop Professionalism in CLS Students}

\author{
EMILY HILL, TERESA S. NADDER, DIANE DODD-MCCUE
}

\begin{abstract}
An increased interest in professionalism is identified as an important topic for the future of healthcare. Educators have an obligation to promote and evaluate students' professional development as well as their knowledge and clinical skills. This study utilized a theatre approach, an innovative teaching strategy, to introduce essential attitudes and behaviors of professionalism to clinical laboratory science (CLS) students. Factors that guide professional behavior in the CLS profession were identified through focus groups of relevant stakeholders. A teaching module, consisting of six case scenarios mirroring real life situations in CLS, was developed based upon the identified professionalism factors. Trained actors produced and performed the scenarios, which incorporated both verbal and non-verbal forms of professional and unprofessional behaviors. Results indicate that a theatre approach is an effective teaching strategy to increase student awareness of professionalism.
\end{abstract}

ABBREVIATIONS: ABIM-American Board of Internal Medicine, APTA-American Physical Therapy Association, ASCP-American Society of Clinical Pathologists, CLS-Clinical Laboratory Science, CLSsClinical Laboratory Scientists, IRB-Institutional Review Board, NAACLS-National Accrediting Agency for Clinical Laboratory Science

INDEX TERMS: Professionalism, Theatre Techniques, Student Development, Unprofessional Behavior

\section{Clin Lab Sci 2015;28(2):91}

Emily Hill, MS, MT(ASCP), Department of Clinical Laboratory Sciences, School of Allied Health Professions, Virginia Commonwealth University, Richmond, VA

Teresa S. Nadder, Ph.D., MLS(ASCP) ${ }^{C M}$, Department of Clinical Laboratory Sciences, School of Allied Health Professions, Virginia Commonwealth University,
Richmond, $V A$

Diane Dodd-McCue, D.B.A., Department of Clinical Laboratory Sciences, School of Allied Health Professions, Virginia Commonwealth University, Richmond, VA

Address for Correspondence: Emily Hill, MS, MT(ASCP), Assistant Chairman, Department of Clinical Laboratory Sciences, School of Allied Health Professions, Virginia Commonwealth University, 301 College St, PO Box 980583, Richmond, VA 23298, 804-628-2979, s2emcrab@vcu.edu.

\section{INTRODUCTION}

Professionalism directly impacts the quality of patient care. Unprofessional behaviors are associated with poor adherence to guidelines, impediment of communication, collaboration, information transfer, workplace relationships, low staff morale and turnover, medical errors, and adverse outcomes. ${ }^{1}$ Clinical laboratory scientists (CLSs) are an integral part of the healthcare team providing physicians with the laboratory results needed to diagnose, manage, and treat patients. As a critical contributor to patient care and outcomes, high and consistent quality of CLS service is demanded regardless of laboratory turnover or retention challenges. To equip students to effectively perform as CLSs and to prepare them for future laboratory leadership roles, CLS educators can nurture student professionalism by incorporating this topic into the undergraduate CLS curriculum. This project contributes to enhancing the professionalism of CLS students by identifying factors that guide professional behavior in CLS and incorporating them in educational goals to foster student professional development. This study examines a novel pedagogical intervention used to accomplish this task.

The standard CLS undergraduate curriculum consists of clinical science courses, application of scientific theory, and technical training. NAACLS Standards require 


\section{EDUCATION}

entry level CLSs to have the basic knowledge and skills in the practices of professional conduct and communications. Student development in the area of professionalism is constrained by time; most programs require two years or less for completion. Integrating professionalism into the curriculum promotes collaborative efforts with other healthcare staff, provides quality patient care, and prepares future laboratorians for management and leadership roles. Identifying the factors that guide CLS professional behavior is a necessary first step in developing an effective teaching approach.

Increasingly, other health professions are expressing concern about student professionalism and its emphasis in entry-to-profession training. In an attempt to foster professionalism, the American Physical Therapy Association (APTA) commissioned a group of 18 physical therapists to develop core professional values. The core values identified by APTA include: accountability, altruism, compassion and caring, excellence, integrity, professional duty, and social responsibility. ${ }^{2}$ The American Board of Internal Medicine (ABIM) defined the elements of professionalism as including altruism, respect for others, honor, integrity, ethical and moral standards, accountability, excellence, duty, and advocacy. ${ }^{3}$ For surgical residents, professionalism was defined as a core competency, with a focus on professional responsibilities to patients and society. ${ }^{4}$ Regardless of their distinct differences, the health services professions share similar challenges in providing patient care.

Research suggests issues of professionalism negatively impact the health care environment, specifically in terms of workforce adequacy. Wynd et al. ${ }^{5}$ reported that problems related to professionalism contributed to the nursing workforce shortage. The workforce issues in CLS parallel those in nursing. The American Society of Clinical Pathologists (ASCP) Wage and Vacancy Survey (2012) reported that the overall vacancy rate in most laboratory departments was approximately 6\%. Nearly half of the clinical laboratories across the nation reported difficulty staffing qualified individuals. Turnover rates for staff level laboratorians are reported to be as high as $30 \%$, and an estimated $13 \%$ of the laboratory staff are likely to retire within the next five years. ${ }^{6}$
Students, the future staff of the clinical laboratory, can anticipate assuming many tasks, including supervisory and management roles in which professional behavior is essential for maintaining a quality workforce. These anticipated demands suggest that educators are obligated to promote clinical and technical skills as well as well as professional development, regardless of potential barriers such as overcrowded curricula and scheduling conflicts. ${ }^{7}$ Francis et al. ${ }^{8}$ suggest that concepts of professionalism be incorporated into CLS curricula and continuing education.

Student professionalism is increasingly a standard component of many healthcare post-baccalaureate curricula. Survey data from over 100 US medical schools found that $90 \%$ include a curricular content that focuses explicitly on professionalism. ${ }^{3}$ Similarly, 318 physical therapy educators from 189 accredited programs indicated that $91 \%$ of their programs emphasize teaching and fostering professional behavior. Seventy-seven percent stated their curriculum included specific modules or courses dedicated to professionalism. $^{2}$

Teaching professionalism begins with a definition to guide what is taught, expected, and evaluated.' The absence of an accepted definition of professionalism, accompanied by varying interpretations among educators, results in inconsistent and erratic student professional development. ${ }^{10}$ Once defined, the question for educators shifts to how professionalism can be effectively introduced and taught to entry-to-profession students.

Theatre techniques, which involve the use of skilled actors, are an innovative teaching modality in CLS. As a pedagogical intervention this approach allows students to experience what is, in essence, a case study acted out "on stage" rather than read or reported. ${ }^{11}$ Further, actors are able to convey verbal and non-verbal forms of communication such as posture, gestures, facial expressions, and eye expressions. Theater techniques can effectively convey information, help participants learn new skills, and promote greater understanding and retention of information. ${ }^{12}$ In short, theatre provides one technique to motivate and inspire learning. ${ }^{13}$

\section{MATERIALS AND METHODS}

This study hypothesizes that incorporating a 
professionalism teaching module into the undergraduate CLS curriculum will increase student awareness and student ability to identify and recognize appropriate and inappropriate examples of CLS professional behavior. This study used a mixed methods design to define CLS professionalism and to introduce and evaluate an educational intervention. The first objective, identifying factors that guide professional behavior in CLS, used focus groups representing unique stakeholders. The factors derived from stakeholder focus groups served as the foundation for the second study objective, developing a professionalism teaching module consisting of six case scenarios delivered by theatre technique, accompanied by a semi-structured discussion and subsequent surveys. The methodology used to address this second objective mirrors the training module design used by Larkin et al., which involved the delivery of vignettes, a pretest, a training session, additional vignettes, and a posttest. ${ }^{14}$

\section{Objective 1- Identifying CLS Professionalism}

Four focus groups convened to identify the factors guiding CLS professional behavior. To ensure data collected would contain a full range of beliefs, experiences, and feelings, these groups represented four unique stakeholders: current CLS students, CLS alumni, CLS educators, and laboratory managers. This study qualified for exemption by the VCU IRB (HM14561).

Individuals were recruited to participate in each respective stakeholder group using purposeful convenience sampling. An electronic invitation recruiting the targeted population was extended to CLS students in a NAACLS accredited program, as well as ASCP certified alumni, educators and laboratory managers in the Commonwealth of Virginia. Inclusion criteria were specific for each targeted stakeholder group. To qualify for participation in the focus groups, the CLS students were undergraduates in good academic and nonacademic standing. The alumni had a minimum of two years of work experience as a CLS. Qualified managers had completed a formal CLS program and have a minimum of two years of experience in a management position. CLS educators currently teach in an adjunct or full-time capacity at an accredited CLS program in Virginia. Twenty individuals from each stakeholder group received this invitation. Those interested in participating were instructed to respond to this invitation with contact information. Five individuals from each of the stakeholder groups volunteered to participate in the focus groups. The resulting focus group size is appropriate for this objective. ${ }^{15}$

The purpose of the focus group sessions was to generate a focused conversation about professionalism among a homogeneous group of students, alumni, managers, or educators representing unique CLS stakeholders. The following questions provided the foundation of the focus group sessions:

- Define professionalism in your own words.

- What factors do you think guide professional behavior in CLS?

- Without identifying specific individuals, provide examples of professional and unprofessional behavior you have witnessed during your time in the profession.

Each session lasted 60-90 minutes. The focus group sessions were recorded and transcribed by a scribe verbatim to assist with data analysis. Thematic content analysis was used to analyzed focus group data, resulting in a list of factors that guide professional behavior in CLS. Investigator triangulation (i.e., the use of more than one researcher to analyze the data) was utilized to ensure that similar conclusions were drawn from the focus group.

\section{Objective 2- Developing, Implementing, and Evaluating a Teaching Module}

The identified professionalism factors served as the foundation for a CLS professionalism teaching module which included six scripted scenarios mimicking real life situations in CLS. Recommendations by Joyner and Young $^{16}$ were used to create the professionalism scenarios: inclusion of specific conditions, inclusion of cases that tap emotions, incorporation of a range of ages, incorporation of cultural diversity, and incorporation of ethical or professional issues. Student actors from the Theater Department at VCU and locally based professional actors, most with experience in theatre technique in health services training, were recruited to perform. The actors' participation included an initial meeting to discuss the scenarios in detail, script, memorization, two practice sessions, and performance on the day of the teaching module. 
A convenience sample of 31 CLS students participated in this study during student orientation. This particular point in the program was chosen to capture undergraduate students at the beginning of an entry-toprofessional program and prior to completion of clinical rotations. This cohort of students had a minimum of two years of undergraduate coursework and no previous work experience in the clinical laboratory. Though it can be assumed that many had worked in other settings, data on work history prior to entry to the program was not collected. During fall semester orientation, the student body was briefed on this project and invited to participate. Those interested completed the consent process; those consenting were identified by a numeric code to protect student confidentiality. Three case scenarios were delivered to participants using a theatre techniques approach. Immediately following, a survey that operationalized professionalism based on the stakeholder focus group results was distributed to the students. Each item was measured by a three response scale: Yes, No, or Behavior Not Observed. Immediately following the survey, students participated in discussion of the first three case scenarios. During this time, the researchers introduced factors of professionalism and explained how traits were linked to CLS practice. Case study reflection was encouraged by asking open ended question, querying the students to explore the issues in the case. ${ }^{16}$ Directly following this discussion, three additional case scenarios were delivered using the theatre techniques approach. Subsequently, a posttest using the same format as the previous instrument was distributed to the students. Response frequency per item and trait and a total score was calculated for each student.

\section{RESULTS}

\section{CLS Professionalism Identification}

A total of 20 individuals, five for each of the four stakeholder group sessions, agreed to participate in focus groups. Each focus group represented one stakeholder category: 1) Laboratory managers/ supervisors, 2) CLS educators, three from hospital based programs and two from university based programs, 3) Alumni of a CLS program, and 4) Current students in a CLS program.

Themes of professionalism common to all stakeholder groups included communication, respectfulness, responsibility, and appearance. However, each of the four groups of CLS stakeholders provided unique interpretation and emphasis of these four factors. Manager and supervisor stakeholders emphasized professionalism in the context of "team work" and "people skills." Unique to this group were attributes related to problem solving, cooperation, and having a positive attitude without frequent complaining. Alumni stakeholders emphasized professionalism in relation to the laboratory's organization and structure (operations) and understanding the role of other professionals on the health care delivery team for the overall goal of patient care. Acceptance of diversity and safety issues was underscored by the alumni. Student stakeholders used their previous work experiences as a basis for their comments. Their discussions highlighted the importance of relating samples to patients, perception by others, and respect for patient and duty to patient (in the absence of a supervisor). A need for structure and tangibles was voiced by the students. Not unexpectedly, this group placed an emphasis on the effect that role models (i.e., instructors, current employees) have on their training, especially with regards to attitude and actions. Educator stakeholders focused on internal qualities/attributes of an individual including trustworthiness, dependability, and assuming responsibility for own learning. The effect of professional involvement and networking on professionalism was stressed as well as self-worth and identity. Understanding the importance of accuracy of test results, reporting critical values and adherence to rules and regulations were included as factors related to professionalism.

\section{Teaching Module Development, Implementation, and Evaluation}

The four factors identified by the stakeholders were the basis for following case scenarios developed by the researchers:

1. a student entering the classroom late for lecture,

2. a student sleeping in class,

3. an unprepared and unfocused student being interviewed for a laboratory position,

4 a medical laboratory scientist who performed an incomplete incubation and desired to leave work early

5 conflict between a medical laboratory scientist (MLS) and health professional over a specimen drop off,

6 a MLS not adhering to dress code. 
The scenarios were scripted to ensure the fidelity and uniformity in the delivery of the educational intervention. The first three scenarios were presented to junior students in a classroom setting; the last three were performed in the student laboratory to mimic the clinical laboratory setting. All scenarios were performed by the trained actors (see Table 1).

Effectiveness was evaluated using surveys administered upon the completion of each set of three case scenarios. Students were asked to check the items on the survey that best represented the behavior witnessed in each case scenario. Table 2 displays the factors of professionalism the actors highlighted in each case scenario and notes the percentage of students correctly identifying each factor. Results from the survey indicated that the majority of students ( $>65 \%)$ were able to identify 19 of the 24 factors. The lowest number of students correctly detecting unprofessional behavior was reported for the fifth scenario; however, many of the students reported that they were unsure which of the two actors in that scene was depicting the medical laboratory scientist. Twelve of the 20 highlighted factors in the remaining four scenarios were recognized by greater than $90 \%$ of the students. Less than $80 \%$ of the students acknowledged that they were able to identify professionalism traits in the scenario that reenacted a job interview in which the applicant appeared not to focus on the interviewer while texting during the interview. Only $66 \%$ of the students indicated that the interviewee displayed nonverbal respect of others by his actions. Total number of factors correctly identified by the students for each scenario is shown in Table 3.

\section{DISCUSSION}

This is the first known study to use stakeholder focus groups to define CLS professionalism. Descriptors of professionalism reported across all stakeholders, including responsibility and respect for others, have been expressed by other health professions. These values, along with the ability to effectively communicate, reflect the necessity to work well as a team in the clinical laboratory. This emphasis on effective team communications is emphasized by other health professionals such as physical therapists and doctors, who more commonly work directly with patients, while CLS professionals are more apt to be working directly or indirectly with other health providers. Appearance was also emphasized by the stakeholders, perhaps in response to recent changes in

Table 1. Scenarios used in Theatre Approach to Professionalism.

\begin{tabular}{|c|c|c|c|c|}
\hline Scenario & $\begin{array}{c}\text { Professionalism } \\
\text { Emphasis }\end{array}$ & $\begin{array}{l}\text { Scenario } \\
\text { Plot }\end{array}$ & Characters & Setting \\
\hline 1 & Professional demeanor & & & \\
\hline & $\begin{array}{l}\text { Nonverbal respect } \\
\text { Tardiness }\end{array}$ & $\begin{array}{l}\text { Student late } \\
\text { for class }\end{array}$ & Instructor, CLS student & Classroom \\
\hline 2 & Professional demeanor & & & \\
\hline & $\begin{array}{l}\text { Nonverbal respect } \\
\text { Display initiative }\end{array}$ & $\begin{array}{l}\text { Student sleeping } \\
\text { in class }\end{array}$ & Instructor, CLS student & Classroom \\
\hline 3 & $\begin{array}{l}\text { Professional demeanor } \\
\text { Focus on task at hand } \\
\text { Nonverbal respect }\end{array}$ & $\begin{array}{l}\text { Unprepared student } \\
\text { interviewed }\end{array}$ & & \\
\hline & Eye contact & & CLS student, interviewer & Classroom \\
\hline 4 & $\begin{array}{l}\text { Professional demeanor } \\
\text { Focus on task at hand } \\
\text { Verbal communication } \\
\text { Nonverbal respect } \\
\text { Positive attitude }\end{array}$ & $\begin{array}{l}\text { MLS performed } \\
\text { incomplete } \\
\text { incubation }\end{array}$ & & \\
\hline & Follow SOP & & MLS, Laboratory supervisor & Laboratory \\
\hline 5 & $\begin{array}{l}\text { Professional demeanor } \\
\text { Verbal communication } \\
\text { Nonverbal respect }\end{array}$ & $\begin{array}{l}\text { Conflict over } \\
\text { specimen drop }\end{array}$ & & \\
\hline & Conflict resolution & off & Two MLSs, Doctor & Laboratory \\
\hline 6 & $\begin{array}{l}\text { Professional demeanor } \\
\text { Adhere to dress code } \\
\text { Work well with others }\end{array}$ & $\begin{array}{l}\text { MLS not adhering } \\
\text { to dress code }\end{array}$ & MLS, Doctor, Resident & Laboratory \\
\hline
\end{tabular}


Table 2. Student observations of professionalism factors highlighted in case scenarios.

\begin{tabular}{|c|c|c|c|c|c|c|}
\hline $\begin{array}{l}\text { Survey Stems/Questions } \\
\text { (Related to Behavior) }\end{array}$ & $\begin{array}{c}\text { Scenario } \\
1\end{array}$ & $\begin{array}{l}\text { Scenario } \\
2\end{array}$ & $\begin{array}{c}\text { Scenario } \\
3\end{array}$ & $\begin{array}{l}\text { Scenario } \\
4\end{array}$ & $\begin{array}{c}\text { Scenario } \\
5\end{array}$ & $\begin{array}{c}\text { Scenario } \\
6\end{array}$ \\
\hline \multicolumn{7}{|l|}{$\begin{array}{l}\text { In the case scenario you witnessed, did the } \\
\text { clinical laboratory scientist: }\end{array}$} \\
\hline Portray him/herself in a professional manner & $100 \%$ & $94 \%$ & $78 \%$ & $97 \%$ & $6 \%$ & $97 \%$ \\
\hline Focus on the task at hand & & $91 \%$ & $75 \%$ & $97 \%$ & & \\
\hline Adhere to dress code & & & & & & $94 \%$ \\
\hline Communicate verbally in a courteous manner & & & & $97 \%$ & $19 \%$ & \\
\hline Display nonverbal respect of others & $91 \%$ & $91 \%$ & $66 \%$ & $84 \%$ & $16 \%$ & \\
\hline Make/maintain proper eye contact & & & $72 \%$ & & & \\
\hline Display a positive attitude & & & & $100 \%$ & & \\
\hline Take initiative & & $78 \%$ & & & & \\
\hline Work well with others & & & & & & $25 \%$ \\
\hline Deals with conflict in a constructive manner & & & & & $25 \%$ & \\
\hline Arrive on time & $94 \%$ & & & & & \\
\hline Follow laboratory testing procedures & & & & $84 \%$ & & \\
\hline
\end{tabular}

Table 3. Student scores on survey of professional factors as demonstrated in case scenarios.

\begin{tabular}{|c|c|c|c|c|c|c|}
\hline Total \# Factors Identified & $\begin{array}{c}\text { Scenario } \\
1\end{array}$ & $\begin{array}{c}\text { Scenario } \\
2\end{array}$ & $\begin{array}{c}\text { Scenario } \\
3\end{array}$ & $\begin{array}{c}\text { Scenario } \\
4\end{array}$ & $\begin{array}{c}\text { Scenario } \\
5\end{array}$ & $\begin{array}{c}\text { Scenario } \\
6\end{array}$ \\
\hline 6 & - & - & - & 62.5 & - & - \\
\hline 5 & - & - & - & 34.4 & - & - \\
\hline 4 & - & 68.8 & 37.5 & 3.1 & 3.1 & - \\
\hline 3 & 84.4 & 25.0 & 25.0 & 0.0 & 6.3 & 18.8 \\
\hline 2 & 15.6 & 0.0 & 21.9 & 0.0 & 9.4 & 28.1 \\
\hline 1 & 0.0 & 6.2 & 9.4 & 0.0 & 15.6 & 3.1 \\
\hline 0 & 0.0 & 0.0 & 6.2 & 0.0 & 65.6 & 0.0 \\
\hline
\end{tabular}

personal protective equipment and more frequent dress code mandating the use of scrubs, in addition to interactions between laboratorians and other health care professionals. ${ }^{2,3,4}$

Differences in the interpretation or emphasis of professionalism observed across stakeholder groups reflect the unique and varied experiences of each stakeholder category. While the managers/supervisors stressed team work within the confinements of the clinical laboratory, the alumni comments suggested an appreciation and respect for the roles of other health care professionals, and their interactions with the clinical laboratory to provide excellence in patient care. Students were still grappling with understanding the full identity of the medical laboratory scientist, expressing a need for tangibles and role models.
Educators, who are often physically removed from the clinical setting, concentrated more on qualities that would contribute to personal growth in the profession.

The teaching module created from stakeholder input was the basis for scenarios delivered using the theatre approach as an innovative intervention at the start of the educational program. The theatre approach is entertaining and unique method not often used in the classroom. A satisfaction survey was given to participants at the end of the professionalism workshop to assess quality and content delivery. All students strongly disagreed or disagreed that a lecture format for presenting this topic was preferred over the theatre approach. In addition, all students either strongly agreed or agreed that the theatre approach to teaching professionalism was effective at presenting examples of 
unprofessional behavior, an effective way of raising awareness of professionalism, and useful in identifying unacceptable behavior in the workforce. If impractical or unfeasible to hire actors annually, the case scenarios can be recorded for later educational use. The surveys evaluating whether students could identify professional and unprofessional behavior demonstrated that not all students are cognizant of expectations as health care professionals. Educating newly admitted students hopefully will increase their awareness of professional behavior and reduce the occurrence of behavioral problems in the classroom and clinical settings. If this technique is implemented, the results of the student surveys could pinpoint those having difficulty identifying unprofessional behavior for further counseling by their advisor even though the survey data is potentially influenced by self -report bias.

Other recommendations include using a tiered classroom design with a stage for the case scenario enactments. In this study the student laboratory used to enact three of the case scenarios was not ideal: while it provided a realistic setting, students were unable to observe all actions of the actors, compared to the raised platform or stage settings. This limitation may have affected the survey results.

It is also difficult to predict the long term effect of the theatre presentations on student behavior with only one post intervention observation. Future studies can include a follow-up session in which the educational intervention is repeated several months after the CLS orientation program or while students are in clinical rotations to compare survey results from the first educational module. As this study suggests, enhancing the professionalism of new entrants to CLS offers rich opportunities yet unexplored.

\section{ACKNOWLEDGEMENT}

The authors would like to acknowledge the ASCLS
Education and Research Member Grant Award for funding to complete this project.

\section{REFERENCES}

1. Van Mook W, Gorter S, De Grave W, Van Luijk S, Wass V, Zwaveling J, et al. Bad apples spoil the barrel: Addressing unprofessional behavior. Medical Teacher 2010; 32:891-8.

2. Davis D. Teaching Professionalism: A Survey of Physical Therapy Educators. J Allied Health 2009;38(2):74-80.

3. Archer R, Elder W, Husted C, Milam A, Joyce J. The theory of planned behavior in medical education: a model for integrating professionalism training. Med Educ 2008;42:771-7.

4. Iramaneerat C. Instruction and Assessment of Professionalism for Surgery Residents J Surg Educ 2009;66(3):158-62.

5 . Wynd CA. Current factors contributing to professionalism in nursing. J Prof Nurs. 2003;19(5):251-61.

6. Bennet A, Thompson N, Holliday B, Brigbee A, Steward C. ASCP wage and vacancy survey of U.S. medical laboratories. Lab Medicine 2009;40(3):133-41.

7. Brehm B, Breen P, Brown B, Long L, Smith R, Wall A, Warren N. An interdisciplinary approach to introducing professionalism. Am J Pharm Educ 2006;70(4):81.

8. Francis D, Hofherr L, Peddecord, K, Karni, K, Krolak, J. The influence of perceived professional status on the career progression of CLS graduates. Clin Lab Sci 2001;14(3):160-6.

9. Cruess R. Teaching professionalism. Clin Orthop Relat Res 2006;449:177-85.

10. Hammer D, Berger B, Beardsley R, Easton M. Student professionalism. Am J Pharm Ed 2003;67(3):1-29.

11. Savitt T. Medical readers' theater as a teaching tool. Camb Q Healthc Ethics 2010;19(4):465-70.

12. Patow C, Bryan D. Engaging physicians in CME: the power of theater. Minn Med 2010;93(11):38-40.

13. Dow A, Leong D, Anderson A, Wenzel R. Using theater to teach clinical empathy: a pilot study. J Gen Intern Med 2007; 22(8):1114-8.

14. Larkin C, Cahan M, Whalen G, Hatem D, Starr S, Lyn HH, et al. Human emotion and response in surgery (HEARS): a simulation-based curriculum for communication skills, systems-based practice, and professionalism in surgical residency training, J Am College Surgeons 2010;285-92.

15. Krueger, RA, Casey, MA. Focus Groups- A Practical Guide for Applied Research. Thousand Oaks, CA: Sage Publications, 2009.

16. Joyner B, Young L. Teaching medical students using role play: twelve tips for successful role plays. Medical Teacher 2006; 28(3):225-9. 